\author{
A. Kurmangaliyev \\ Master of Arts in Digital Technologies, Communication and Education \\ Master of Science in Educational Leadership \\ alibek.kurmangaliyev@astanait.edu.kz,orcid.org/0000-0002-9469-4431 \\ Astana IT University, Kazakhstan
}

\title{
ISSUES OF ICT INTEGRATION IN RURAL SECONDARY SCHOOLS OF KAZAKHSTAN
}

\begin{abstract}
The problem with attaining education equality for various categories of the population has been one of the priority topics of social and political studies. Kazakhstan has recently stated the aim to ensure equal access for all participants in the educational process to the best resources and technologies. However, half of all state schools are in rural areas and supporting them is often inadequate in comparison to urban schools. These schools have minimal infrastructure, for example, a lack of proper Internet access and professional development opportunities for teachers. The barriers to information and communication technologies in education seem to be one of the main issues for teaching staff in rural settings. The purpose of this research was to explore the issues of ICT integration in teaching and learning processes among secondary school teachers. This multiple case study explored the experiences of eight instructors from three rural schools through semi-structured interviews, lesson observations, and curriculum analysis. The results reveal evidence of the very poor quality of the Internet in visited rural schools. The findings also demonstrate that teachers often have to use their personal mobile phones at work despite the ban from administration. This, along with the poor technological capability of the schools, negatively affects the educational process in visited schools.
\end{abstract}

Keywords: ICT in education, rural schools, digital gap, qualitative research, multiple case study, Kazakhstan.

\section{Introduction}

The present stage of development in society is characterized by changes in all spheres of our life. These changes may significantly affect the requirements for the education system. General education is designed to ensure conditions for the successful socialization of students, the realization of their abilities, opportunities and interests. This indicates the need for changes in the organization and management of the whole educational process in Kazakhstan [22]. Studying the impact of ICT on a person seems to be one of the most important tasks of pedagogy in modernization of the current education system in the country. Currently, there is a rapid process occurring in the development of information, which is characterized, first of all, by the widespread introduction of modern information technologies in various spheres of human activity [8]. Trends in the development of modern society and its informatization explain the need for the increasing use of information technologies in education.

The level of education in a rural school in Kazakhstan is commonly characterized by informational isolation of students and teachers, known limitations on the use of technologically based visual demonstration aids and equipment. Only with a certain system of ICT usage in 
the student learning process we can possibly assure that there is learning through technology tools in classrooms. The problem of insufficient use of ICT in Kazakhstan urban schools is an issue in some areas, but the lack of use of ICT in rural schools seems to be even more concerning. Poor technical conditions of rural schools in Kazakhstan and its inadequate funding is a regular matter of discussion. Additionally, there seems to be a problem in providing highspeed Internet to rural schools and villages as a whole. The readiness of teachers to provide quality education to their students using ICT also remains a big problem in Kazakhstan's rural education system $[11,20]$.

A theoretical analysis of the literature shows that there are a number of studies devoted to rural schools and various aspects of their operation. Kazakhstan is not the only country facing the difficult task of providing quality education in large rural areas where the villages are located at a considerable distance from each other, the use of transport is limited, and the road network is not sufficiently developed. For developed countries like Canada, Finland, Australia, Sweden, and Portugal, such characteristics as low population density and extensive rural areas are very common. An analysis of these countries' experience in the organization of the educational process in rural schools may provide the necessary guidelines for the modernization of the educational system of Kazakhstan [2].

The problem of education equality and accessibility of education for various categories of the population appears to be one of the priority topics of social and political studies throughout the world. OECD experts developed a definition of "equality" in education which is used to refer to "an educational and learning environment in which individuals can consider options and make choices throughout their lives, taking into account their abilities and talents, rather than stereotypes, prejudiced hopes or discrimination" [23]. Such an environment seems to provide economic and social opportunities regardless of gender, ethnicity, race, social status or geographic location.

Many studies have proven that applying ICT has a beneficial impact on the quality of teaching and learning because it improves students' engagement, encourages their individual learning and finally, it helps educators to enhance their traditional ways of teaching by using different applications or devices in the classroom to better engage the learners [8, 9, 12]. Thus, the introduction of ICT contributes to the achievement of the main goal of education modernization. This includes improving the quality of education, increasing accessibility of education as well as ensuring the development of students' ICT skills.

Not all schools in Kazakhstan have the same access to a modern global education. According to OECD report, $57 \%$ of all state schools are ungraded with far higher proportions in Northern Kazakhstan (86\%) and Kostanay region (76\%). Because of vast territories, the majority of secondary schools in Kostanay region represent small ungraded educational institutions and schools from rural areas. These schools have minimal infrastructure, for example, a lack of proper Internet access and professional development opportunities for teachers. The barriers to ICT and poor Internet connection seem to be one of the main current issues for such schools [15].

This problem can negatively affect students because they may not have the same access to quality education as students from bigger cities. For instance, it could influence their future admissions to higher education institutes or technical - vocational colleges as they are required to pass the standardized Unified National Test upon finishing their secondary education [18]. Thus, in the context of educational modernization, studying the influence of ICT on students and how this may hinder their intellectual development is probably one of the most important goals of pedagogical science. The study was guided by the following research question: What issues of ICT integration in classroom do educators face in their practice? 


\section{Inequality in education: school location factor}

The problem of educational inequality seems to be a common issue in most countries. Some of the factors that raise disparities in education are unprivileged social groups, cultural inequality, and territorial inequality. Barriers to access to quality education in the countryside are the features of resettlement and the socio-economic situation of rural areas, which is usually much lower than in cities. It should be noted that along with this, active urbanization continues. The population of large cities is growing, the population of small and mediumsized villages is declining. In addition, the situation becomes even more dramatic as the most energetic and capable segment of youth leave rural communities, whose professional aspirations are identical to that of young city dwellers [1]. Over the past fifteen years, the number of ungraded schools in Kazakhstan has increased dramatically. According to the Concept, almost one in every four Kazakh teachers works in an ungraded school and one in every six Kazakh students attends school in a rural location [4].

The overwhelming majority of schools in rural areas are still inferior to urban schools in terms of their provision of all kinds of amenities. To solve this problem, considerable efforts have been made in recent years by regional authorities in Kazakhstan e.g. the closure and reorganization of rural schools, the creation of a system of base schools providing transportation for students, the supplying of equipment, the development of distance learning. However, it appears that the problem remains unresolved [2].

\section{Issues of rural schools}

A narrative case study conducted by Febriana, Nurkamto, Rochsantiningsih, and Muhtia examined the challenges of eighteen English language teachers in Indonesia teaching in eighteen different rural schools. The researchers applied open-ended questionnaires and individual interviews with those teachers. The findings of this project demonstrated several challenges faced by Indonesian teachers who taught in rural schools. Some of the most essential challenges were infrastructure, inadequacy of teachers, language barrier and parents' mindset [5]. Thus, this country is experiencing great difficulties in providing quality education in rural schools. Similarly in Kazakhstan, the level of teaching and learning process in rural schools continues to be inadequate. In Kazakhstan's case, there appears to be many problems such as low salaries of rural school teachers, old communication infrastructure, transportation, and inadequate monitoring of academic quality in schools. One question that needs to be asked, however, is whether these issues are solvable.

Kerimbayev et al. in their study interviewed one principal of a rural school in Southern Kazakhstan on the topic of difficulties experienced in rural schools. The findings demonstrate the three major problems: inability of teachers to work in rural school settings, infrastructure and unpreparedness of teachers to use equipment, and isolation of the school from urban places. The researchers of this study reached the conclusion that most of the problems of today's Kazakhstan ungraded schools can be solved by introducing e-learning system in the education process [11].

On the basis of the evidence currently available in OECD 2014, it seems fair to say that secondary students in Kazakhstan attending urban schools perform much better in national and international tests [15]. In OECD 2010, moderate results for reading was 376 points for students of rural schools, 383 for students in towns and 419 for students in large cities and 431 for students in the biggest cities of Kazakhstan Nur-Sultan and Almaty [14]. Further evidence may lie in the analysis of Unified National Testing [26]. There are 3,268 rural schools in the country, 1,655 of which are secondary schools. The overall average score of remote schools was 74.97 points, which is lower than the indicator for the country by 4.45 points, and in specialized schools for Gifted children by 21.02 points. The lack of subject teachers and 
language of instruction could also negatively affect learning outcomes. This is certainly true in the case of Kostanay region's lowest scores in Kazakh language [2]. Hopkins developed the claim in one of his ten principles that "when the focus of policy is on the quality of teaching rather than structural change, then student achievement will increase" [10]. In other words, the ministry of education should focus on implementing educational reforms that could raise the level of excellence in our teaching staff.

The problems of the rural school are not a matter of preserving one of the types of educational institutions. It is a national problem connected with the destiny of the state itself. Having analysed the theoretical material and methodological literature about the features of the educational process in rural schools, it can be concluded that today rural education is one of the most urgent problems in the system of education. Rural schools comprise a significant portion of all schools in Kazakhstan. The quality of the students' preparation in rural schools influences the level of knowledge in the whole country [11]. Therefore, it is necessary to improve the quality of teaching and the resource base, as well as to find ways to implement innovative teaching technologies more effectively.

\section{Other contexts and Kazakhstan}

Yu, Di, Linxiu, Boswell, Rozelle studied ICT integration into teaching programmes in Chinese rural schools in 2016. They used a clustered randomized controlled trial design in 127 rural schools of China. The findings show that student test results in studying English language improved relative to the schools where ICT programmes were integrated with teaching. Therefore, an example of ICT assisted instruction in Chinese rural setting demonstrates the effectiveness of ICT and benefit to student performance [25].

Sangrà and González-Sanmamed in their multiple case study research analyzed the contribution of ICT to the development of teaching and learning processes in Spain. To collect data, they interviewed the school administration; reviewed strategic reports, teaching plans and gave surveys to teachers. A total number of 1,222 teachers took part in this research. From the findings, it is clear that using ICT in teaching as "favouring several processes related to teaching and learning - in particular, those involving attention, perception, responding mechanisms, application of learning and understanding" [19].

Kim and Kim in their study aimed at exploring the perceptions of teachers in 21 South Korean rural schools regarding their technology preparedness and integration of tablets in classrooms. The participants included 54 Korean teachers from rural schools. The results of this study indicate that student performances are correlated with the frequent use of tablets in their lessons. Furthermore, the respondents stated they often use such devices to increase their students' motivation [12].

Similarly, Helmer, Harper and Wolgemuth found through their research that primary education teachers from Australia's Northern Territory confirmed the value gained from using technology for educational purposes. The research examined teacher's values and expectations of technologies in education. However, there were some barriers for rural teachers to fully integrate ICT in lessons such as the lack of human resources as well as poor professional development [9].

Kazakhstan seems to be on its way to fully integrate ICT in schools. However, this appears to be more possible for urban schools than remote ones. Analysis highlights some issues related to material and technical conditions of ungraded schools in Kazakhstan. Firstly, there is lack of use of ICT in all kinds of schools. Secondly, in many rural schools there is out-of-date infrastructure to support telecommunications. While $11.5 \%$ of rural schools are connected to broadband Internet, only $28 \%$ of such schools are equipped with interactive equipment that can be used to support the lesson. In 1834 rural schools there are no Physics classrooms, in 
2554 schools-no Chemistry classrooms, in 2525 schools-no Biology classrooms, and in 85 schools-no Computer Science classrooms [2].

The main reason for ineffectiveness of the current Kazakhstan education in villages are possible disparities in the infrastructure of urban and rural schools [13]. Another issue of these schools is lack of professional development for teaching staff when it comes to applying ICT in the class. Most schools are located far from large urban centres. As a result, teachers work in isolation, which probably contributes little to the growth of their professional skills [11].

It is widely accepted that applying ICT has a beneficial impact on the quality of teaching and learning because it improves students' engagement, encourages their individual learning and finally, it helps educators to enhance their traditional ways of teaching by using different apps or devices in the classroom. To address the problems of educational inequality and technological gap, various measures could be proposed including supporting socioeconomically disadvantaged students, the introduction of information technology, distance education, and the differentiation of education [24].

\section{Methodology and design}

A qualitative research design was chosen to conduct this study. This design has some advantages that make it attractive and most suitable to this research. One of them is "it provides a unique example of real people in real situations, enabling readers to understand ideas more clearly than simply by presenting them with abstract theories or principles" [3]. The multiple or collective case study was determined to be the best approach for this project to explore how teachers in three rural schools may use ICT in their classrooms and the problems they encounter. The researcher conducted this project at several sites to illustrate different experiences of rural teachers. A multiple case study approach can incorporate different types of data and it provides an in - depth perspective. This design allowed the researcher to understand the similarities and differences between the different cases of the three rural schools in Kostanay region of Kazakhstan. Additionally, multiple cases allow deep analysis of the research questions and theories. Some of the limitations of multiple case study approach are discussed in the work of Gerring [6]. For example, the more case studies the research includes, the less time the researcher spends on observations and data collection. For this reason, this research was limited to three cases only.

\section{Schools}

As mentioned earlier, the main focus of this research were secondary mainstream schools in remote areas of Kostanay region of Kazakhstan. The data collection was conducted in three schools in rural areas, which are characterized by a low number of students and multigrade levels, known as ungraded schools. The first school (S1) is located ten kilometres south of Kostanay city and it is characterized by a large number of students. This is a secondary education mainstream school with grades 1-11 and it has the largest enrolment among all the sites of this study. The second research site (S2) is five kilometres drive from the (S1) school. The place is also 1-11 year secondary school, however it is half the size in comparison to the first school (S1). Lastly, the ungraded school (S3) was visited in another remote area of the region. This school is the only education institution of the village where about 1,200 residents live. This institution is characterized by a very low number of students and staff, poor supply and infrastructure, and the main school building is very decrepit and desperately in need of major renovations. 


\section{Participants}

A total of eight participants were recruited for this study. The participants were teachers of different subjects in the three secondary rural schools of Kostanay region. Also, the teachers were selected based on their language of instruction. There were participants who taught in Kazakh language, and those who taught in Russian language. Gender wise, both male and female participants were chosen for this study. Thus, participants with different characteristics had various perspectives and views on this qualitative research.

The Table 1 below shows the information about the respondents who participated in the individual semi - structured interviews. Each school was given its own code such as S1, S2 and S3. The three schools differ from each other in the number of students, distance from the city and ICT equipment. Each teacher was given a code T1, T2 or T3 to ensure confidentiality of all participants. In total, eight teachers took part in individual interview which lasted approximately 30 minutes. Working experiences at the respective school was between 4 and 30 years. Also, teachers taught in subject areas such as Mathematics, Languages, Primary Education and Sciences. Participation of all the teachers was on a voluntary basis.

Table 1. Characteristics of Participants

\begin{tabular}{|c|c|l|c|c|c|}
\hline Pseudonym & $\begin{array}{c}\text { Teaching } \\
\text { experience }\end{array}$ & \multicolumn{1}{|c|}{ Subject } & Grade level & School size & $\begin{array}{c}\text { Distance from } \\
\text { the city }\end{array}$ \\
\hline S1T1 & 28 years & Primary school & Year 1 & 800 students & 10 kilometres \\
\hline S1T2 & 22 years & Mathematics & Year $9-11$ & 800 students & 10 kilometres \\
\hline S1T3 & 9 years & English language & Year $1-3$ & 800 students & 10 kilometres \\
\hline S2T1 & 25 years & $\begin{array}{l}\text { Kazakh language and } \\
\text { literature }\end{array}$ & Year 8 & 600 students & 15 kilometres \\
\hline S2T2 & 4 years & English language & Year $1-11$ & 600 students & 15 kilometres \\
\hline S2T3 & 30 years & Biology & Year $5-11$ & 600 students & 15 kilometres \\
\hline S3T1 & 29 years & $\begin{array}{l}\text { Russian language and } \\
\text { literature }\end{array}$ & Year 5-10 & 150 students & 20 kilometres \\
\hline S3T2 & 18 years & Chemistry & Year 7-11 & 150 students & 20 kilometres \\
\hline
\end{tabular}

\section{Instruments}

The researcher applied the following data collection tools as single semi - structured interviews, reviewing several subject program descriptions and lesson plans, and direct observations of lessons. The purpose of such instruments was to develop a deep understanding of the current issues in rural secondary school education in Kazakhstan. Overall, the researcher conducted eight individual semi - structured interviews in Russian language that took no more than 30 minutes each. Another data collection instrument was curriculum analysis including lesson plans and subject programs. This was a great way of exploring how school teachers in Kostanay region use ICT in their practice. Additionally, this tool was widely used by other scholars in similar research studies [17, 21]. Using these tools in combination with other collection tools allows triangulation of the data. Lastly, several lesson observations were conducted in this study in order to develop insight into the lesson context and activities used by the teacher in the lesson, particularly those that involved integrating ICT.

\section{Findings. Quality of internet connection}

One of the main topics that all participants highlighted was the poor quality of the Internet in their schools. Although it was evident that only two schools out of three were connected to broadband or wireless Internet, the connection of the Internet for those schools was still very 
slow. For the first school (S1), the main reason was the large number of computers connected to the network. In the second school (S2) there were not enough computers, but the Internet speed was also very slow, too. The last school (S3) did not have any wireless or broadband cable network available for teachers and students. One respondent reported that the problems with the quality of the Internet interferes with providing the best quality of education. She commented:

We have very old wires and when it rains or snows outside, the Internet disappears completely. We always prepare a second plan in case the Internet is lost during the lesson.

Another interviewee said that the lack of Internet in rural areas means that teachers buy the mobile Internet $(\mathrm{Wi}-\mathrm{Fi})$ at their own expense. Her response was:

The quality of the Internet is very low. At home, the Internet is a bit better, so we do most of our work at home.

From the observations it was evident that without the Internet, it is difficult to improve the level of professionalism of rural school teachers. The teachers cannot use electronic educational resources such as Kazakh platforms Bilim Land, Bilim All, and e-Learning. In order to use digital platforms, they need access to the Internet at a speed of more than 10 Megabytes per second (Mbit/s). In rural schools S1 and S2, the average speed varied from 2.5 to 4 Mbit/ s. With such speed, it is impossible to use electronic educational resources in the classroom as it takes far too long for the pages to load. Thus, it was clear that almost all teachers use their personal computers, laptops at work. They also have to use personal Internet modems, which they pay for themselves. Old computers and low-quality Internet connection in these rural schools does not allow the interviewees to teach and self-develop in the same way that those in urban schools can.

\section{Mobile phones}

Interestingly, some participants commented that mobile phones are used sometimes as educational tools in their classrooms. The most popular reason why they include students' personal mobile phones in the classroom was finding information while working individually or in groups. From the classroom observations, it became evident that not all classrooms in all three schools are equipped with a desktop computer and an interactive board. Therefore, educators from remote schools, where the number of technologies was extremely limited were among those who integrated the use of cellular phones the most.

For a student, a telephone is not only a means of communication, it is both a calculator and an organizer, they can quickly take pictures or write something down. This is another great alternative to enriching the lesson. There were real examples provided when the phone became useful in the lesson. They used applications that were downloaded prior to the lesson to the phone of a teacher and students. Those applications allowed a teacher to instantly assess the response of her students.

Another surprising response was on the issue of permission to allow the use of phones in the lesson by the administration of the schools. One of the respondents S1T2, a Math teacher with 22 years of experience mentioned:

Despite the fact that there is no official permission for students to use the phones, I consider it necessary to use gadgets in the classroom. A complete ban on use is not good. Each teacher and student needs to be able to use them correctly.

This shows that a mobile phone can become a new student tool in class in remote areas, along with a textbook and a notebook, although some school principals did not allow students and teachers to bring their mobile phones to school. Therefore, this seems to be a barrier which further impinges upon the process of mobile learning at schools. 


\section{Equipment and Infrastructure}

Two-thirds of the participants felt that there were not enough personal computers for students and teachers. For example, the respondent S2T3 stated that only three or four laptops work properly at her school: "I do not understand what is with the laptops in our school?"

Only one participant S1T1 indicated that she was more or less satisfied with the technical equipment at her school whereas, the majority agreed on the fact that even if there are some laptops at school, they mostly do not work, or are in a very old and poor condition. Additionally, from observations it was evident that only the first school (S1) was equipped with a desktop computer in each classroom. In contrast, at the third school (S3) there was only one classroom with a computer and an interactive board. One of the teachers S3T2 commented:

We have one single computer room which is always occupied. The school is too full and there is no possibility to get into this room. We need to request in advance from the administration to conduct a lesson there.

The review of the reports from three schools added more data on the number of school computers used by the students. The Table 2 below shows the ratio of students per computer in all three schools. It can be seen that the ratio is much different in comparison to the Nazarbayev Intellectual School in the city (NIS). Therefore, equipment and infrastructure of rural schools needs much improvement, and it is clear that these schools are underfunded. This increases the present gap and the social injustice between students from urban districts and those who come from rural areas.

Table 2. Ratio of Students and Personal Computers

\begin{tabular}{|l|c|c|c|}
\hline \multicolumn{1}{|c|}{ Research site } & $\begin{array}{c}\text { Approximate number of } \\
\text { students }\end{array}$ & $\begin{array}{c}\text { Number of personal } \\
\text { computers }\end{array}$ & $\begin{array}{c}\text { Ratio of computer per } \\
\text { students }\end{array}$ \\
\hline School 1 (S1) & 800 & 35 & $1: 23$ \\
\hline School 2 (S2) & 600 & 5 & $1: 120$ \\
\hline School 3 (S3) & 150 & 1 & $1: 150$ \\
\hline NIS school & 650 & 700 & $1: 0.9$ \\
\hline Average in Kazakhstan schools [16] & & $1: 13$ \\
\hline
\end{tabular}

The evidence of poor internet connection and a low number of learning technologies was discussed during the interviews with the respondents. In addition, it is clear that some teachers experience barriers such as poor conditions of technologies or even an absence of them. Based on the curriculum analysis of some subjects, the updated curriculum requires teachers to integrate ICT in every lesson, but this renewed curriculum does not take into account the problems with ICT equipment in rural schools. S2T2 said: "we do not have the resources to follow the curriculum. Some students do not have computers at home, or even mobile phones". Additionally, some educators mentioned other barriers they encounter when working in their schools such as multi grade teaching and doing different jobs in addition to teaching.

\section{Discussion and Conclusion}

It was evident that all three rural schools of Kostanay region were not well equipped with proper working ICT to enhance the education process. This finding further supports the idea of Febriana et al. that rural schools are always under-equipped with high technologies and resources in comparison to schools in cities [5]. Zhang also reported the huge gap in investments between rural and urban education in China [27]. Additionally, some buildings of the schools visited in this study were in terrible condition. A possible explanation for this result may be the lack of adequate financing of rural schools from Kazakhstan government. Improving the 
performance of students in rural mainstream schools through increasing access to educational materials and equipping them with multimedia equipment should be considered a top priority. Future studies on this topic are therefore recommended.

This study found that among all the problems of rural schools the most striking was the poor quality of both wireless and mobile Internet. In all three cases the speed of the Internet negatively affected the educational process. For example, without a high-speed Internet, keeping and filling out the electronic assessment portal Kundelik becomes impossible. The need for broadband Internet is dictated by modern reforms in Education of the Republic of Kazakhstan. It is likely that the transition to the updated program and trilingual policy, the introduction of a new system of teachers' certification has been affecting every teacher in the country. Learning these innovations takes a lot of time and therefore, having a good Internet will help to successfully implement these reforms.

The ratio of students and computers in rural schools is much different in comparison with other mainstream schools in the city. Rural schools continue to be underfunded resulting in a digital gap between urban and rural education institutions in the education system of Kazakhstan. The results show that even though all the teachers stated they believe ICT is a powerful educational tool, not everyone had an opportunity to fully integrate it in their classroom. Teachers from some schools are choosing to provide a laptop and the Internet USB modem at their own expense so that they can use technology to complement their lessons. Many students from rural schools are not able to use the Internet, but also work with computers as the ratio of computers per student is very low meaning there are not enough computers for each student. As with findings of $Y u$ et al. the present study provides additional evidence with respect to present educational inequality in the system of education [25].

Finally, the results show that even though all the teachers stated they believe ICT is a powerful educational tool, not everyone had an opportunity to fully integrate it in their classroom. Teachers from some schools are choosing to provide a laptop and the Internet USB modem at their own expense so that they can use technology to complement their lessons. Many students from rural schools are not able to use the Internet, but also work with computers as the ratio of computers per student is very low meaning there are not enough computers for each student. The present study provides additional evidence with respect to present educational inequality in the system of education in Kazakhstan.

It is recommended that further investigation is undertaken in the use of mobile phones by students and teachers in rural schools. Based on some responses of this study, teachers are forced to use mobile phones because the schools do not provide opportunities to access computers with high speed Internet. Further research work needs to be done to establish the extent teachers are competent in the use of ICT including some new devices provided by education departments in each region. Some participants of the study stated they did not know how to use electronic laboratory appliances. Therefore, a possible future research study could explore the significance of ICT professional development courses for teachers from rural schools in Kazakhstan.

\section{References}

1. Abankina, T., Krasilova, A., \& Yastrebov, G. (2012). Education as a Start in Life: Life Plans of Rural High School Students in Russia. Educational Studies, (2), 87-120.

2. Pons, A., Amoroso, J., Herczynski, J., Kheyfets, I., Lockheed, M., \& Santiago, P. (2015). OECD Reviews of School Resources.

3. Cohen, L., Manion, L.\& Morrison, K. (2007). Research Methods in Education 6th edition. USA: Taylor \& Francis e-Library, 250-255. 
4. Concept of development of ungraded schools in the Republic of Kazakhstan for 2010-2020 (2011). Astana, Ministry of Education and Science of Kazakhstan, 2-17.

5. Febriana, M., Nurkamto, J., Rochsantiningsih, D., \& Muhtia, A. (2018). Teaching in rural Indonesian schools: Teachers' challenges. International Journal of Multicultural and Multireligious Understanding, 5(5), 11-20.

6. Gerring, J. (2004). What Is a Case Study and What Is It Good for? The American Political Science Review, 98(2), 341-354.

7. Gewirtz, S. (2006). Towards a contextualized analysis of social justice in education. Educational Philosophy and Theory, 38(1), 69-81.

8. Ghavifekr, S., \& Rosdy, W. A. W. (2015). Teaching and learning with technology: Effectiveness of ICT integration in schools. International Journal of Research in Education and Science, 1(2), 175-191.

9. Helmer, J., Harper, H., \& Wolgemuth, J. (2018). Teachers' Values and Expectations of Technology in Northern Territory Primary Schools. The Eurasia Proceedings of Educational and Social Sciences, 10, 156-162.

10. Hopkins, D. (2013). Exploding the myths of school reform. School Leadership \& Management, 33(4), 304-321.

11. Kerimbayev, N., Akramova, A., \& Suleimenova, J. (2016). E-learning for ungraded schools of Kazakhstan: Experience, implementation, and innovation. Education and Information Technologies, 21(2), 443-451.

12. Kim, H. J., \& Kim, H. (2017). Investigating teachers' pedagogical experiences with tablet integration in Korean rural schools. The Asia-Pacific Education Researcher, 26(1-2), 107-116.

13. Kudasheva, T., Kunitsa, S., \& Mukhamediyev, B. (2015). Effects of access to education and information-communication technology on income inequality in Kazakhstan. Procedia-Social and Behavioral Sciences, 191, 940-947.

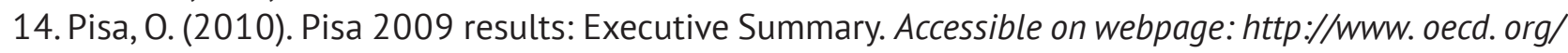
pisa/pisaproducts/46619703. pdf Retrieved, 12(09), 2014.

15. OECD (2014). Reviews of National Policies for Education: Secondary Education in Kazakhstan, OECD Publishing. http://dx.doi.org/10.1787/9789264205208-en.

16. OECD (2015). Students, Computers and Learning: Making the Connection, PISA, OECD Publishing. http://dx.doi.org/10.1787/9789264239555-en

17. Pelgrum, W.J. (2001). Obstacles to the integration of ICT in education: results from a worldwide educational assessment, Computers \& Education, 37(2), ISSN 0360-1315, https://doi.org/10.1016/ S0360-1315(01)00045-8, pp. 163-178.

18. Rules for conducting a unified national testing (2011). Ministry of Science and Education in Kazakhstan, 5 December 2011, №506 https://adilet.zan.kz/rus/docs/V1100007367

19. Sangrà, A., \& González-Sanmamed, M. (2010). The role of information and communication technologies in improving teaching and learning processes in primary and secondary schools. Australasian Journal of Educational Technology, 26(8), 207-220

20. Sapargaliyev, D., \& Shulenbayeva, K. (2013). Informatization of Kazakhstani higher education. Procedia-Social and Behavioral Sciences, 83, 468-472.

21. Selwyn, N. (2004). The information aged: A qualitative study of older adults' use of information and communications technology. Journal of Aging studies, 18(4), 369-384.

22. State Program of Education Development (SPED) in Kazakhstan for 2011-2020 (2010). Astana, Republic of Kazakhstan, December 7, 1118. https://adilet.zan.kz/rus/docs/U1000001118

23. UNESCO (2012). The Global Monitoring Report on Education for All. Paris, UNESCO Publ., p.44

24. Yamaletdinova, A.M., \& Medvedeva, A.S. (2016). Modern information and communication technologies in the educational process. Bulletin of the Bashkir University, 21(4), 1134-1141.

25. Bai, Y., Mo, D., Zhang, L., Boswell, M., \& Rozelle, S. (2016). The impact of integrating ICT with teaching: Evidence from a randomized controlled trial in rural schools in China. Computers \& Education, 96, 1-14.

26. Zabara, L., Boranbayeva, S. (2015). Analysis of Unified National Testing 2015, Astana, Kazakhstan: AO IAC, 6-55.

27. Zhang, H. (2017). Opportunity or new poverty trap: Rural-urban education disparity and internal migration in China. China Economic Review, 44, 112-124. 